\title{
Clarifying the mechanism of idiopathic macular hole development in fellow eyes using spectral-domain optical coherence tomography
}

This article was published in the following Dove Press journal:

Clinical Ophthalmology

19 January 2011

Number of times this article has been viewed

\section{Mikiko Takezawa \\ Fumihiko Toyoda \\ Chiho Kambara \\ Hiroko Yamagami \\ Akihiro Kakehashi}

Department of Ophthalmology, Jichi Medical University, Saitama Medical Center, Saitama, Japan
Correspondence: Akihiro Kakehashi Department of Ophthalmology, Jichi Medical University, Saitama Medical Center, I-847 Amanuma-cho, Omiya-ku, Saitama-shi, 330-8503, Japan

$\mathrm{Tel}+8 \mathrm{I} 486472 \mathrm{III}$

Fax+8I 486485188

Email kakeaki@omiya.jichi.ac.jp
Background: To clarify the mechanism of idiopathic macular hole development, we evaluated the vitreoretinal relationship in fellow eyes of those with a macular hole and normal eyes using spectral-domain optical coherence tomography. Thirty-one fellow eyes and 34 normal volunteer eyes without a posterior vitreous detachment (PVD) were included.

Results: We classified six vitreomacular relationships: type 1, no PVD, five fellow eyes (16.1\%) and nine control eyes (26.5\%); type 2, shallow PVD with perifoveal vitreous attachment, seven fellow eyes (22.6\%) and 19 control eyes (55.9\%); type 3, shallow PVD with pinpoint foveal vitreous traction, seven fellow eyes (22.6\%) and no control eyes ( $0 \%$ ), type $4 \mathrm{a}$; shallow PVD with a round defect in the posterior vitreous cortex over the perifoveal area with vitreous attachment to the perifoveal area, two fellow eyes (6.5\%) and one control eye (2.9\%); type 4b, shallow PVD with a round defect in the posterior vitreous cortex over the perifoveal area without vitreous attachment to the perifoveal area, no fellow eyes $(0 \%)$ and one control eye $(2.9 \%)$; type $5 \mathrm{a}$, shallow PVD with no pseudo-operculum, no fellow eyes $(0 \%)$ and four control eyes $(11.8 \%)$; type 5b, shallow PVD with a pseudo-operculum, four fellow eyes (12.9\%) and no control eyes $(0 \%)$; and type 6, biomicroscopically relevant PVD, six fellow eyes (19.4\%).

Conclusion: Types 3 and 5 b developed only in fellow eyes. Type 2 developed most often in normal eyes and seemed to cause less foveal stress. Type 3 may show the basic pathogenesis of macular holes. Progression of type $5 b$ after type 3 induces abortion of developing macular holes.

Keywords: idiopathic macular hole, optical coherence tomography, posterior vitreous detachment, fellow eye

\section{Introduction}

Although the pathogenesis of the development of idiopathic macular holes is attributed to vitreous traction on the fovea associated with a shallow posterior vitreous detachment (PVD) based on observation of the vitreoretinal relationship with optical coherence tomography (OCT),${ }^{1-9}$ the entire scenario of macular hole development remains uncertain. ${ }^{7,10}$ Before OCT was introduced, many reports had postulated that idiopathic macular holes resulted from vitreous traction on the foveal retina without evidence of a PVD, based on observation of the vitreoretinal relationship by slit-lamp biomicroscopy. ${ }^{10-15}$ Two major mechanisms, anteroposterior vitreous traction (A-P traction) and tangential vitreous traction (tangential traction) on the foveal retina, cause idiopathic macular holes. In 1983, Avila et al, ${ }^{11}$ who reported the vitreoretinal findings of idiopathic macular holes based on biomicroscopic findings using the El Bayadi-Kajiura lens, speculated that A-P traction was the main mechanism of 
development of idiopathic macular holes because of a slight upshift of the operculum above the surface of the foveal retina without a PVD. This is the classical A-P traction theory of the development of idiopathic macular holes. In contrast, in 1988, Gass ${ }^{13}$ postulated the pathogenesis of idiopathic macular holes based on observation of the vitreoretinal relationship by slit-lamp biomicroscopy using a Goldmann three-mirror lens and showed the developmental stages of idiopathic macular holes. The diagram of the developmental stages of idiopathic macular holes showed the operculum to be at the same level of the foveal retina at stage 3 macular holes, suggesting that tangential traction caused the macular hole. This is the classic tangential traction theory of the development of an idiopathic macular hole. However, Gass later noticed shifting of the operculum above the surface of the foveal retina in stage 3 macular holes, and in 1995, he revised his diagram of the developmental stages of idiopathic macular holes. ${ }^{12}$ Kakehashi et al ${ }^{10}$ reported movement of the operculum in stage 3 macular hole cases with no PVD, and suggested that idiopathic macular holes are more likely to develop as a result of A-P traction. Both theories accept that there is no PVD in stage 3 macular holes, and therefore, PVD does not contribute to the initial pathogenesis of macular holes. However, a different theory has arisen with the advent of OCT. OCT images of macular holes have shown that shallow PVDs and pinpoint vitreous traction on the fovea seem to exist. ${ }^{1-9}$ However, it is still uncertain whether A-P traction or tangential traction is the main mechanism of development of macular holes. In the current study, we postulated the mechanism of macular hole formation based on observation of the vitreomacular relationship in the fellow eyes of those with a macular hole and in normal eyes using spectral-domain OCT (SD-OCT).

\section{Methods}

We observed the vitreomacular relationships in the fellow eyes of 31 patients (age range 49-81 years; mean 66.4 years; mean best-corrected visual acuity [BCVA], 20/80 in macular hole eyes and 20/20 in fellow eyes) with an idiopathic fullthickness macular hole and 34 normal volunteer eyes without biomicroscopically relevant PVD (age range 41-73 years, mean 59.2 years; mean BCVA, 20/20). The examination focused on the vitreomacular relationship observed on SDOCT (Cirrus ${ }^{\mathrm{TM}}$ HD OCT, Carl Zeiss Meditec, Dublin, CA). A dynamic biomicroscopic vitreoretinal examination was performed using slit-lamp biomicroscopy (SL130, Carl Zeiss Meditec) and a preset lens (SuperField NC Lens, Volk, Mentor, OH). ${ }^{16}$
Only the complete PVD type was diagnosed by slitlamp biomicroscopy. Scanning with the Cirrus HD-OCT was performed using a five-line raster scan program (length, $6 \mathrm{~mm}$ or $9 \mathrm{~mm}$ ). The following six classifications of shallow PVDS were identified by SD-OCT: type 1, no PVD; type 2, shallow PVD with perifoveal vitreous attachment; type 3, shallow PVD with pinpoint foveal vitreous traction; type $4 \mathrm{a}$, shallow PVD with a round defect in the posterior vitreous cortex over the perifoveal area with vitreous attachment to the perifoveal area; type $4 \mathrm{~b}$, shallow PVD with a round defect in the posterior vitreous cortex over the perifoveal area without vitreous attachment to the perifoveal area; type 5a, shallow PVD with no pseudo-operculum; type 5b, shallow PVD with a pseudo-operculum; and type 6 , biomicroscopically relevant complete PVD (Figure 1).

\section{Results}

We classified the vitreomacular relationships in fellow eyes of those with a macular hole and in normal eyes (see Table 1). Types 3 and $5 \mathrm{~b}$ were observed only in the fellow eyes of those with a macular hole and not in normal eyes. Type 2 was observed most frequently in normal eyes. In type $5 \mathrm{~b}$, a pseudo-operculum was found on the detached posterior vitreous cortex by SD-OCT but was not detected by biomicroscopy. The prevalence of each type in both groups differed significantly ( $P<0.01$ by $\chi^{2}$ test) when eyes with type 6 were excluded.

\section{Discussion}

The prevalence rates of bilateral macular holes have been reported to range from $0 \%$ to $29 \% .{ }^{17}$ Therefore, the fellow eyes of macular hole cases may show early changes in the natural course of developing macular hole. Before the introduction of OCT, biomicroscopy was the best way to evaluate vitreoretinal relationships in eyes with a macular hole. At that time, the pathogenesis of macular holes was unknown. Macular holes rarely develop in eyes with a complete PVD. Even stage 1 and 2 macular holes can return to normal after a complete PVD, ${ }^{17,18}$ indicating that vitreous traction must be the most important factor in the development of macular holes. However, there is no evidence of biomicroscopic PVD during development of macular holes until stage 3. Biomicroscopically evident PVD can be seen in stage 4 macular holes. Therefore, the classic A-P traction theory of Avila et $\mathrm{al}^{11}$ and the classic tangential traction theory of $\operatorname{Gass}^{13}$ were postulated as mentioned previously. Kakehashi et al, ${ }^{10}$ using biomicroscopy, reported movement of the operculum above the level of the retinal surface in 


\section{Type 1}

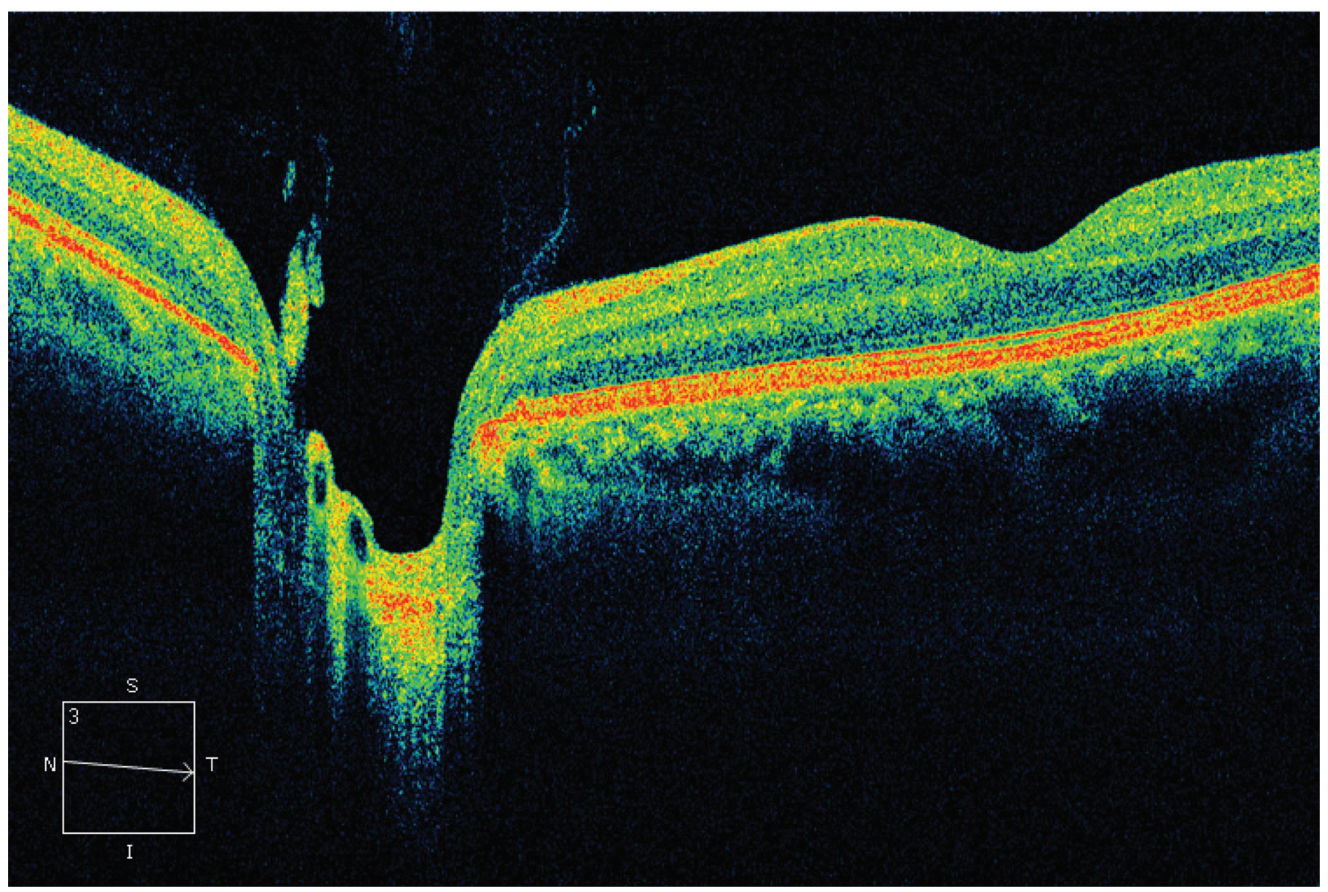

Type 2
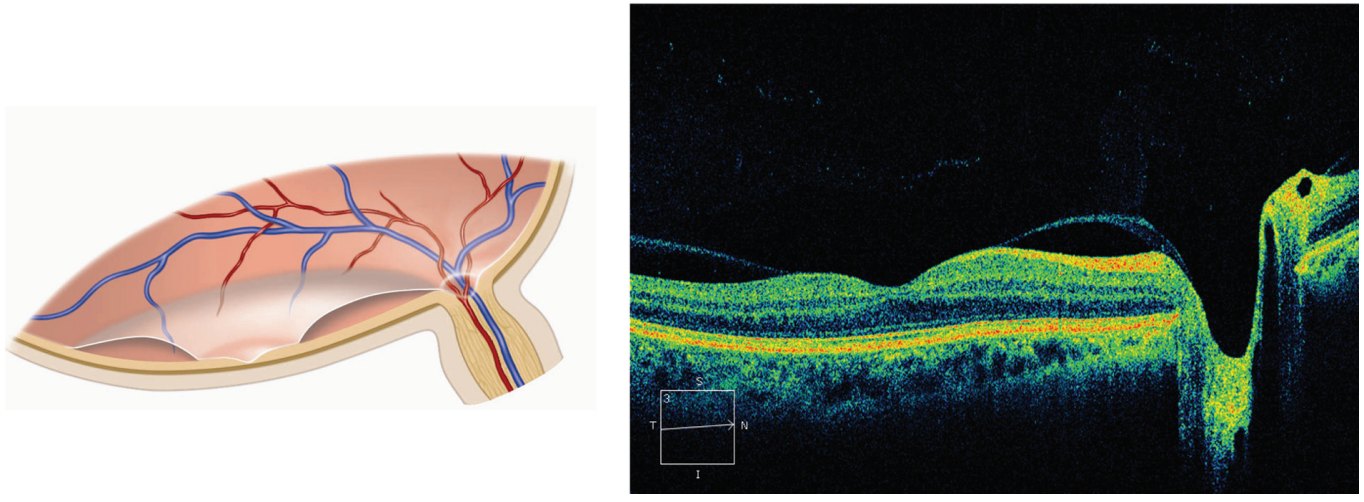

\section{Type 3}
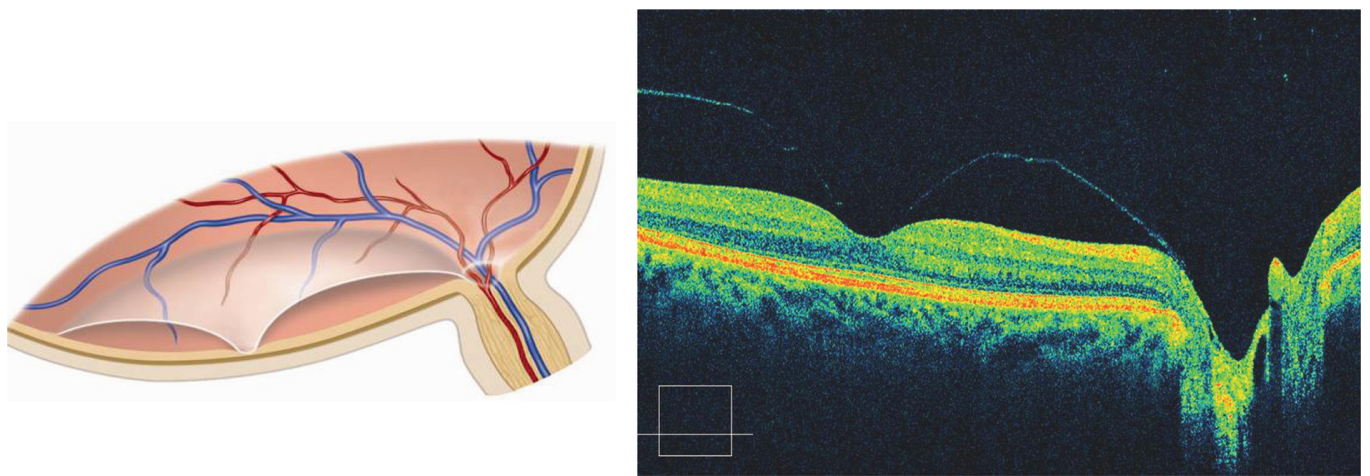

Figure I Classification of a shallow posterior vitreous detachment (PVD). Type I, no PVD. Type 2, shallow PVD with a perifoveal vitreous attachment. Type 3, shallow PVD with pinpoint foveal vitreous traction. Type 4a, shallow PVD with a round defect in the posterior vitreous cortex over the perifoveal area with vitreous attachment to the perifoveal area. Type 4b, shallow PVD with a round defect in the posterior vitreous cortex over the perifoveal area without vitreous attachment to the perifoveal area. Type 5a, shallow PVD with no pseudo-operculum. Type 5b, shallow PVD with a pseudo-operculum. 
Type 4a
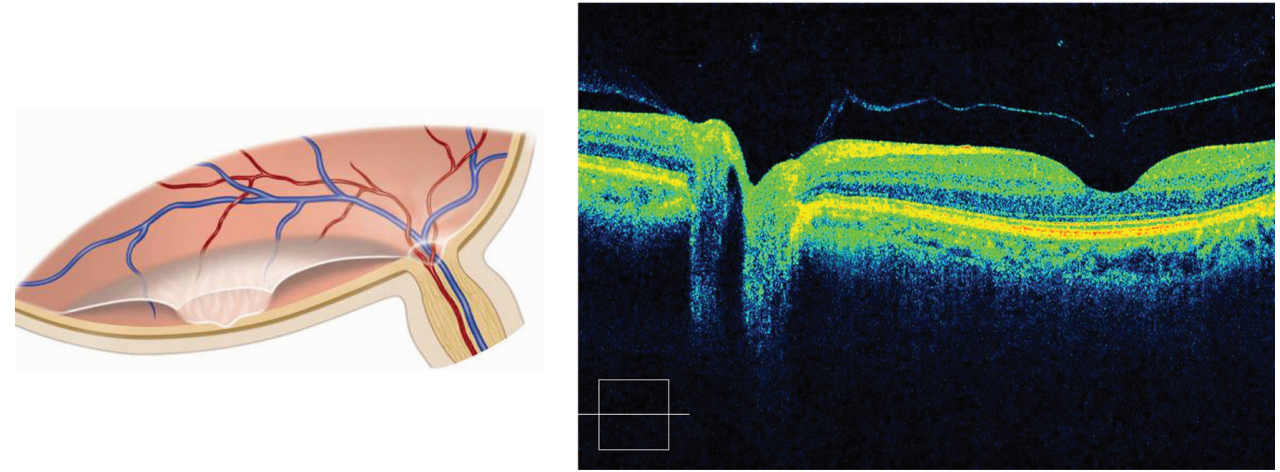

Type 4b
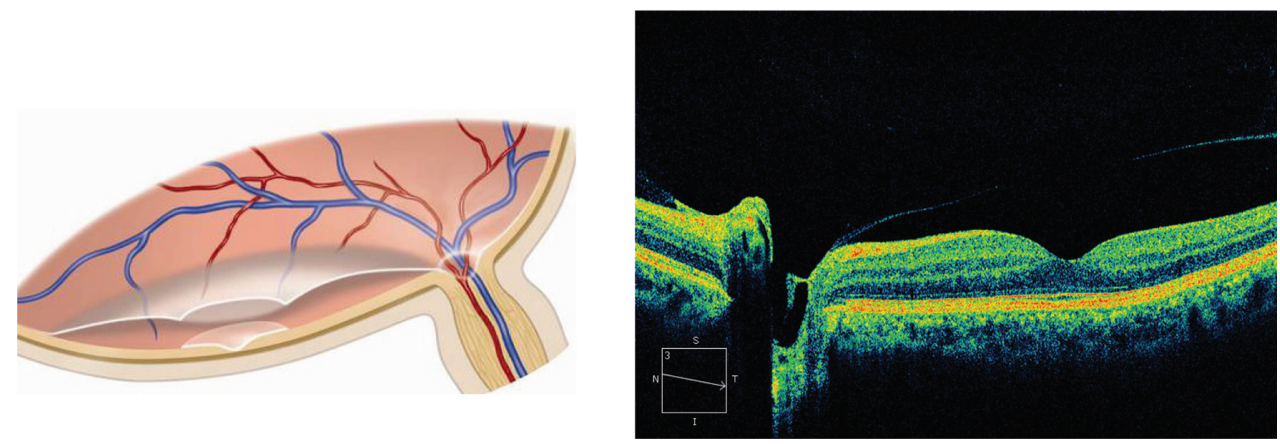

Type 5a
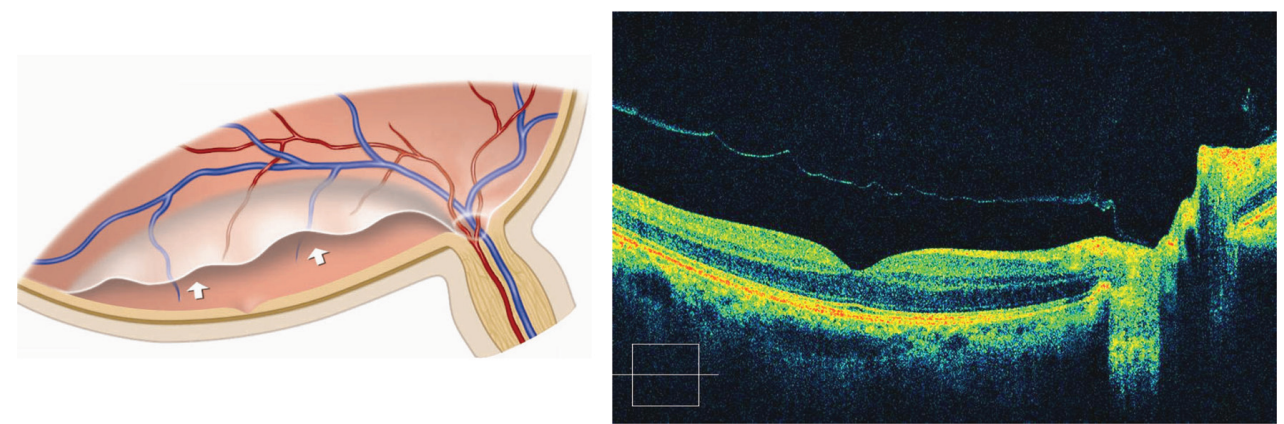

Type 5b
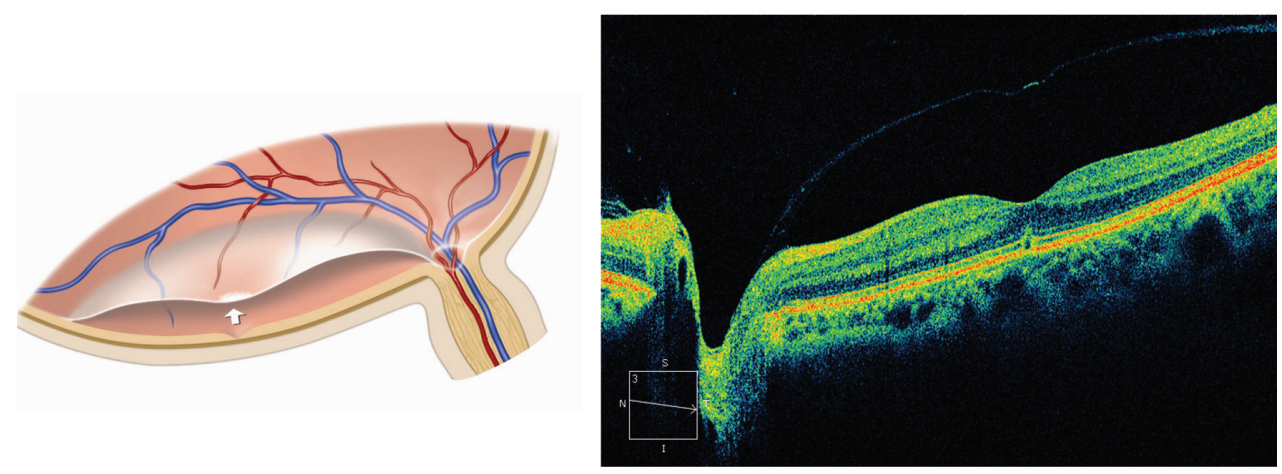

Figure I (Continued) 
Table I Prevalence of each type of shallow posterior vitreous detachment in fellow eyes of those with a macular hole and normal eyes

\begin{tabular}{lll}
\hline Type & $\begin{array}{l}\text { Fellow eyes of macular } \\
\text { hole }(\mathbf{n}=\mathbf{3} \mathbf{I}) \\
\mathbf{n}(\%)\end{array}$ & $\begin{array}{l}\text { Normal eyes } \\
(\mathbf{n}=\mathbf{3 4}) \\
\mathbf{n}(\%)\end{array}$ \\
\hline $\mathrm{I}$ & $5(16 . \mathrm{I})$ & $9(26.5)$ \\
2 & $7(22.6)$ & $19(55.9)$ \\
3 & $7(22.6)$ & $0(0)$ \\
$4 \mathrm{a}$ & $2(6.5)$ & $\mathrm{I}(2.9)$ \\
$4 \mathrm{~b}$ & $0(0)$ & $\mathrm{I}(2.9)$ \\
$5 \mathrm{a}$ & $0(0)$ & $4(11.8)$ \\
$5 \mathrm{~b}$ & $4(12.9)$ & $0(0)$ \\
6 & $6(19.4)$ & $\mathrm{NA}$ \\
\hline
\end{tabular}

Abbreviation: NA, not applicable.

stage 3 macular holes but did not detect a shallow PVD by biomicroscopy (Figure 2). Gass ${ }^{12}$ also reported shifting up of the operculum in stage 3 macular holes, and he revised his initial diagram of the developmental stages of macular hole accordingly. After OCT was introduced, both the classic A-P traction theory and the classic tangential traction theory were found to be incorrect. There is no doubt that shallow PVDs with vitreous traction to the fovea observed by OCT but not by slit-lamp biomicroscopy cause macular holes. However, it is still uncertain how shallow PVDs develop and how they cause macular holes. Some reports have suggested that tangential traction is the pathogenesis of macular holes. Kishi and Takahashi, ${ }^{19}$ using time-domain OCT, speculated that tangential contraction of the premacular vitreous cortex generates anterior traction that results in a "trampoline-like" shallow PVD in the macular area associated with a posterior vitreous pocket. If so, the posterior vitreous cortex should be taut and show no movement of the operculum in stage 3 macular holes. In fact, quite a few cases of stage 3 macular

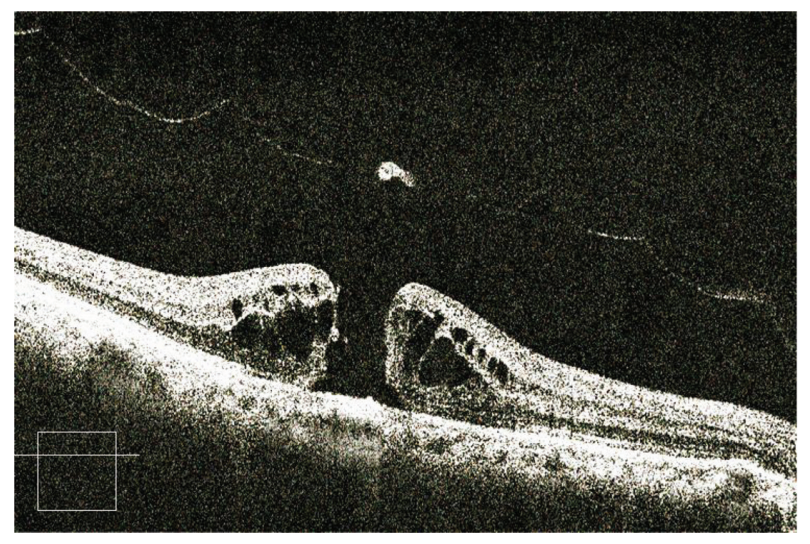

holes have shown movement of the operculum in association with ocular movement. ${ }^{10}$ This finding of a detached operculum on the shallowly detached loose posterior vitreous cortex was observed by SD-OCT more clearly than by timedomain OCT (Figure 2). ${ }^{20}$ Even in stage 2 macular holes, a detached posterior vitreous cortex shows some movement (Figure 3). ${ }^{20}$ Other studies have reported OCT findings of a dome-shaped or trampoline configuration of a shallow PVD with vitreous adhesion to the fovea. These changes cause oblique vector force on the fovea and subsequent A-P traction on the fovea. ${ }^{2,21,22}$ From these findings, the new theory of A-P traction seems to be the correct mechanism of developing macular holes.

In the current study, in which we compared the findings of vitreofoveal relationships in fellow eyes of those with a macular hole and in normal eyes, types 3 and $5 \mathrm{~b}$ were seen only in the fellow eyes of those with a macular hole and not in normal eyes. Firm vitreofoveal adhesion combined with vitreopapillary adhesion ${ }^{23}$ and an anteriorly oriented shallow PVD cause pinpoint traction on the fovea, ${ }^{1-9}$ which seems to be the basic pathogenesis of macular holes (Figure 4). Niwa et al performed a follow-up study of fellow eyes of those with a macular hole using time-domain OCT and reported that vitreous traction to the fovea caused the development of full-thickness macular holes in the fellow eyes of those with a macular hole. ${ }^{6}$ In contrast, in normal eyes, type 2 was the most frequent type, in which no pinpoint vitreous traction was exerted on the fovea. There are two possible primary scenarios in the development of a normal age-related PVD. In the early stage of development of age-related PVD, a type 5 shallow PVD may be the stage before the development of biomicroscopically evident PVD. Johnson ${ }^{24}$ postulated this, and we also found type 5 shallow PVDs in the

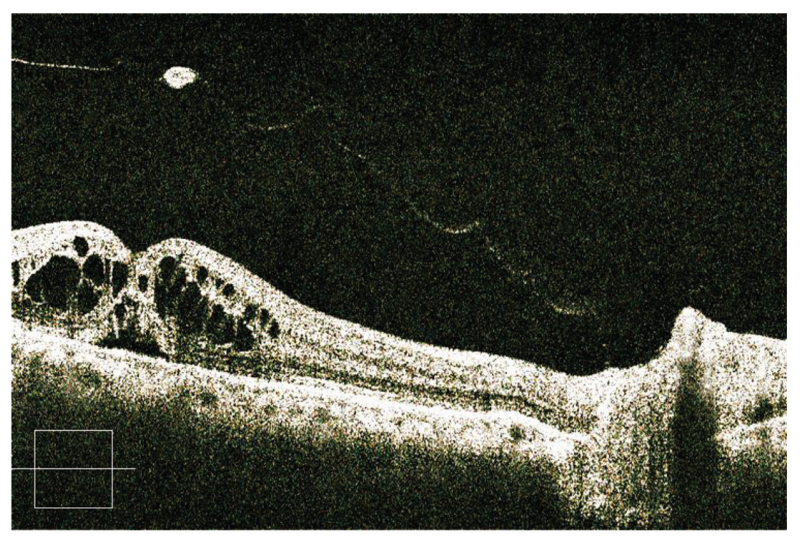

Figure 2 Movement of a detached operculum on the shallowly detached loose posterior vitreous cortex. Both optical coherence tomography images were obtained from the same patient. The left image was obtained just after ocular movement in the right image. Modified from Kakehashi. ${ }^{20}$ 

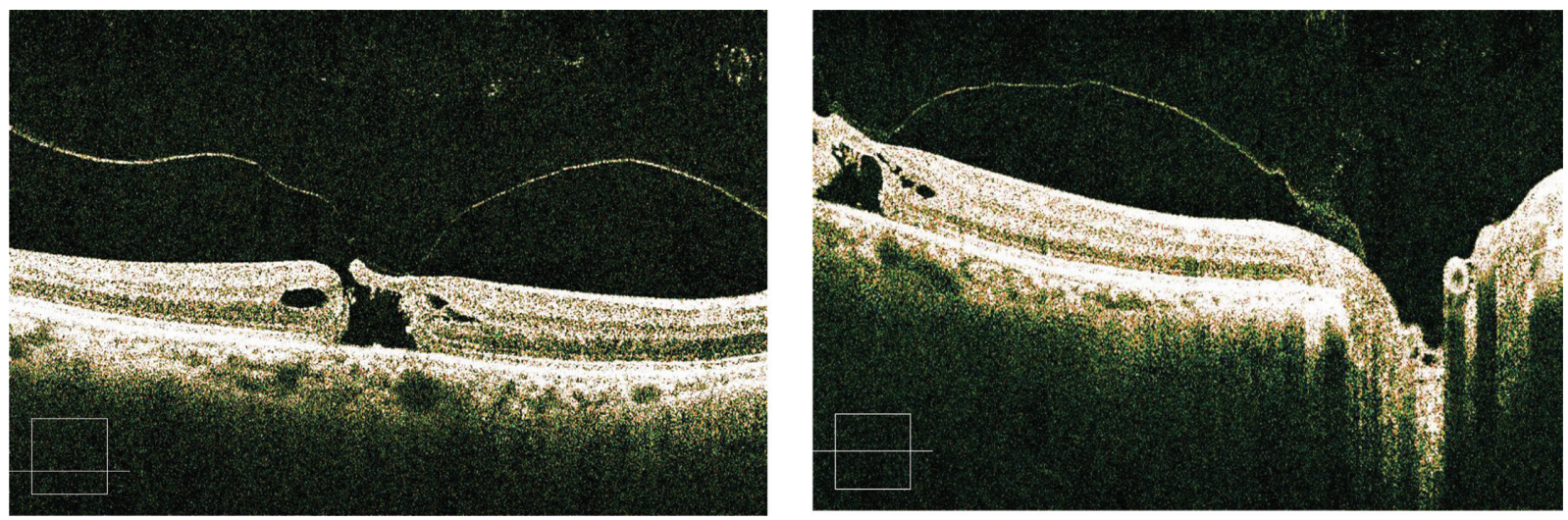

Figure 3 The vitreoretinal relationship in a stage 2 macular hole. The detached loose posterior vitreous cortex shows some movement and traction to the operculum. Both optical coherence tomography images were obtained from the same patient. The left image is that of the central section of the macular hole, and the right image is the off-center section of the macular hole.

Modified from Kakehashi. ${ }^{20}$

normal control eyes. Another scenario is that a type 4 shallow PVD is the stage before development of biomicroscopically evident PVD. The wide vitreous attachment around the fovea in type 2 seems to be less stressful for the fovea, which is the thinnest part of the retina. Intrusion of liquefied vitreous into the subhyaloid space seems to induce shallow PVDs both in macular hole cases and normal eyes. The liquefied vitreous probably moves through a crevice in the glial ring on the optic disc into the subhyaloid space over the macular area. The liquefied vitreous trapped in the subhyaloid space pushes the detached posterior vitreous cortex anteriorly both in fellow eyes of those with a macular hole and in normal eyes. However, it is difficult to explain the differences between the pinpoint vitreous attachment in fellow eyes of
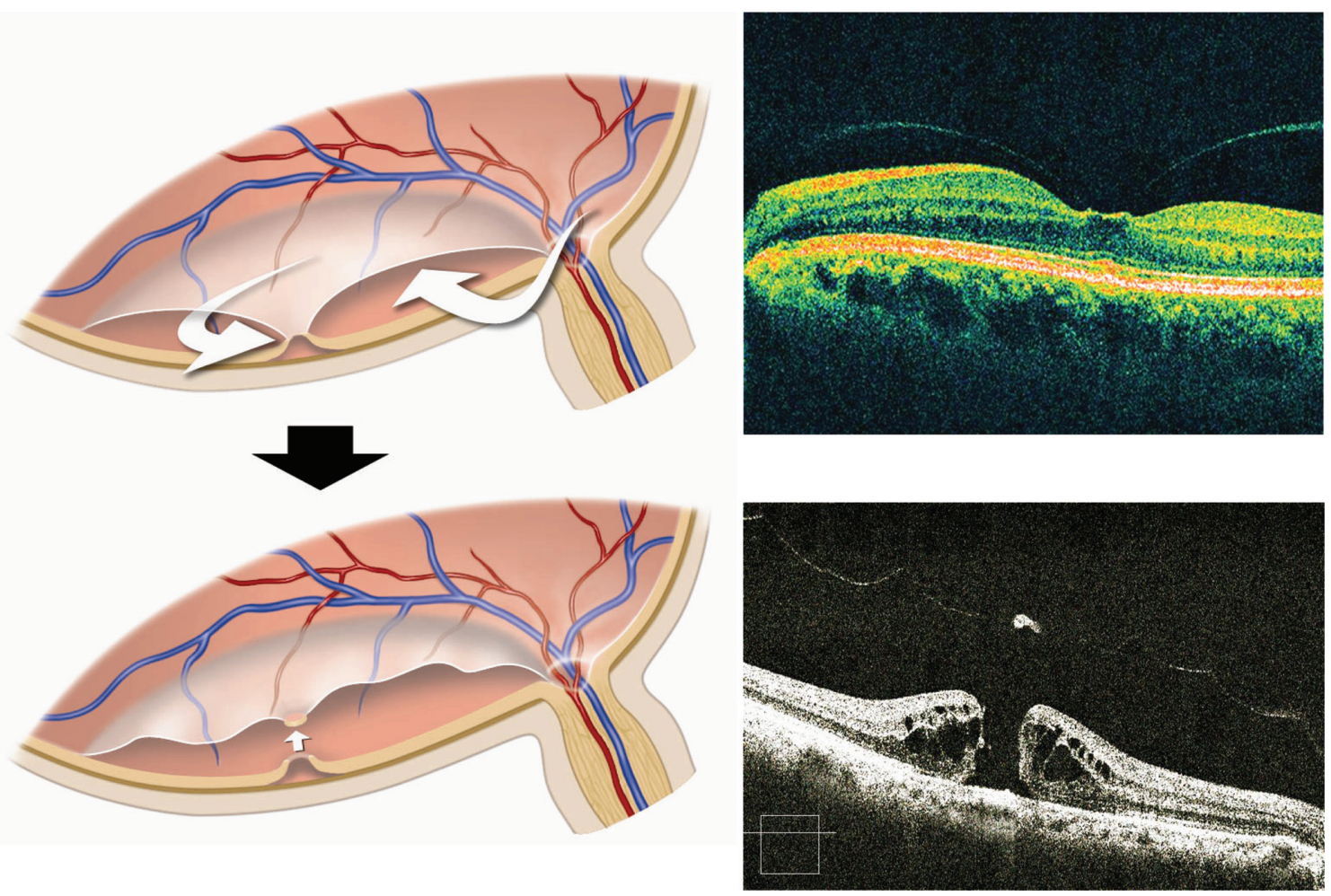

Figure 4 Mechanism of a developing macular hole. The upper images show that the liquefied vitreous enters the subhyaloid space over the macular area through a crevice in the glial ring on the optic disc. The liquefied vitreous trapped in the subhyaloid space pushes the detached posterior vitreous cortex anteriorly with adhesion to the fovea (upper images) and subsequently causes development of a macular hole (lower images).

Modified from Kakehashi. ${ }^{20}$ 
those with a macular hole and the wide vitreous attachment around the fovea in normal eyes. In normal eyes, round defects in the premacular cortical vitreous are seen frequently by biomicroscopy, ${ }^{25}$ scanning laser ophthalmoscopy, ${ }^{26}$ and in vitro slit-lamp microscopy. ${ }^{27}$ In contrast, these round defects in the premacular cortical vitreous and a coexisting remnant of cortical vitreous on the macula are not as common in fellow eyes of those with a macular hole as in normal eyes. Types $4 \mathrm{a}$ and $4 \mathrm{~b}$ are rarely seen in fellow eyes of those with a macular hole or normal eyes. These types seem to follow type 2 . The reason why these types are rare may be explained by the fact that more liquefied vitreous may enter the subhyaloid space through the round defect in the posterior vitreous cortex, and in that case a biomicroscopic PVD occurs immediately under those conditions (Figure 5). A biomicroscopic PVD with a round defect in the posterior vitreous cortex over the perifoveal area is seen frequently in both clinical cases and autopsy eyes.

In conclusion, types 3 and $5 b$ were observed only in the fellow eyes of those with a macular hole and not in normal eyes. Type 2 was observed most frequently in normal eyes. The pinpoint vitreous traction to the fovea, the thinnest part of the retina, in type 3 seems to be the basic pathogenesis of macular holes. Progression of type 5b after type 3 causes developing macular holes to be aborted. In contrast, a shallow

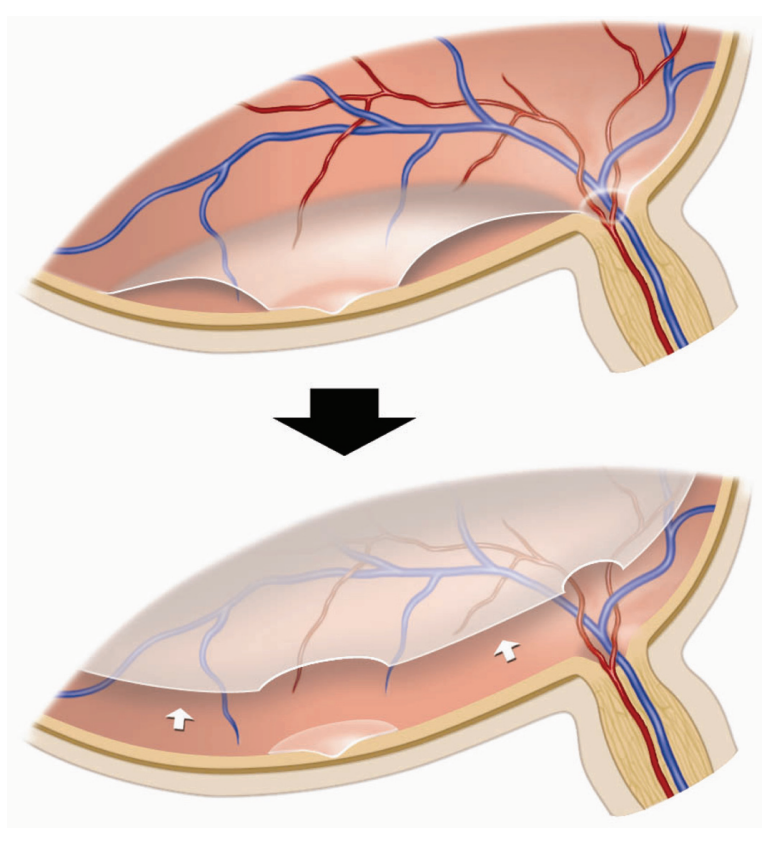

Figure 5 Mechanism of developing ordinary posterior vitreous detachment (PVD). Wide vitreous attachment around the fovea is less stressful to the fovea. After development of a round break in the posterior hyaloid, a large amount of liquefied vitreous enters the subhyaloidal space hastening a biomicroscopic PVD. Modified from Kakehashi. ${ }^{20}$
PVD with wide vitreous attachment around the fovea found in type 2 seems to be less stressful to the fovea.

\section{Disclosure}

The authors report no conflicts of interest in this work.

\section{References}

1. Azzolini C, Patelli F, Brancato R. Correlation between optical coherence tomography data and biomicroscopic interpretation of idiopathic macular hole. Am J Ophthalmol. 2001;132(3):348-355.

2. Gaudric A, Haouchine B, Massin P, Paques M, Blain P, Erginay A. Macular hole formation: New data provided by optical coherence tomography. Arch Ophthalmol. 1999;117(6):744-751.

3. Haouchine B, Massin P, Gaudric A. Foveal pseudocyst as the first step in macular hole formation: A prospective study by optical coherence tomography. Ophthalmology. 2001;108(1):15-22.

4. Ito Y, Terasaki H, Suzuki T, et al. Mapping posterior vitreous detachment by optical coherence tomography in eyes with idiopathic macular hole. Am J Ophthalmol. 2003;135(3):351-355.

5. Johnson MW, van Newkirk MR, Meyer KA. Perifoveal vitreous detachment is the primary pathogenic event in idiopathic macular hole formation. Arch Ophthalmol. 2001;119(2):215-222.

6. Niwa H, Terasaki H, Ito Y, Miyake Y. Macular hole development in fellow eyes of patients with unilateral macular hole. Am J Ophthalmol. 2005;140(3):370-375.

7. Smiddy WE, Flynn HW Jr. Pathogenesis of macular holes and therapeutic implications. Am J Ophthalmol. 2004;137(3):525-537.

8. Takahashi A, Nagaoka T, Ishiko S, Kameyama D, Yoshida A. Foveal anatomic changes in a progressing stage 1 macular hole documented by spectral-domain optical coherence tomography. Ophthalmology. 2010;117(4):806-810

9. Tanner V, Chauhan DS, Jackson TL, Williamson TH. Optical coherence tomography of the vitreoretinal interface in macular hole formation Br J Ophthalmol. 2001;85(9):1092-1097.

10. Kakehashi A, Schepens CL, Trempe CL. Vitreomacular observations. II. Data on the pathogenesis of idiopathic macular breaks. Graefes Arch Clin Exp Ophthalmol. 1996;234(7):425-433.

11. Avila MP, Jalkh AE, Murakami K, Trempe CL, Schepens CL. Biomicroscopic study of the vitreous in macular breaks. Ophthalmology 1983;90(11):1277-1283.

12. Gass JD. Reappraisal of biomicroscopic classification of stages of development of a macular hole. Am J Ophthalmol. 1995;119(6):752-759.

13. Gass JD. Idiopathic senile macular hole. Its early stages and pathogenesis Arch Ophthalmol. 1988;106(5):629-639.

14. Trempe CL, Weiter JJ, Furukawa H. Fellow eyes in cases of macular hole. Biomicroscopic study of the vitreous. Arch Ophthalmol. 1986; 104(1):93-95.

15. Hikichi T, Akiba J, Trempe CL. Effect of the vitreous on the prognosis of full-thickness idiopathic macular hole. Am J Ophthalmol. 1993; 116(3):273-278

16. Kakehashi A. Examination technique of vitreous biomicroscopy. In: Schepens CL, Trempe CL, Takahashi M, editors. Atlas of Vitreous Biomicroscopy. Boston, MA: Butterworth-Heinemann; 1999.

17. Ezra E. Idiopathic full thickness macular hole: Natural history and pathogenesis. Br J Ophthalmol. 2001;85(1):102-108.

18. Kakehashi A, Schepens CL, Akiba J, Hikichi T, Trempe CL. Spontaneous resolution of foveal detachments and macular breaks. Am J Ophthalmol. 1995;120(6):767-775.

19. Kishi S, Takahashi H. Three-dimensional observations of developing macular holes. Am J Ophthalmol. 2000;130(1):65-75.

20. Kakehashi A. Mystery of macular hole. In: Kakehashi A, Akiba J, Takahashi M, editors. Biomicroscopic Vitreous Examination. Tokyo: Nakayamashoten; 2008. 
21. Gallemore RP, Jumper JM, McCuen BW 2nd, Jaffe GJ, Postel EA, Toth CA. Diagnosis of vitreoretinal adhesions in macular disease with optical coherence tomography. Retina. 2000;20(2):115-120.

22. Mori K, Abe T, Yoneya S. Dome-shaped detachment of premacular vitreous cortex in macular hole development. Ophthalmic Surg Lasers. 2000;31(3):203-209.

23. Wang MY, Nguyen D, Hindoyan N, Sadun AA, Sebag J. Vitreopapillary adhesion in macular hole and macular pucker. Retina. 2009; 29(5):644-650.

24. Johnson MW. Posterior vitreous detachment: Evolution and complications of its early stages. Am J Ophthalmol. 2010;149(3): 371-382, e371.
25. Kakehashi A, Schepens CL, Trempe CL. Vitreomacular observations. I. Vitreomacular adhesion and hole in the premacular hyaloid. Ophthalmology. 1994;101(9):1515-1521.

26. Kakehashi A, Ishiko S, Konno S, Akiba J, Kado M, Yoshida A. Observing the posterior vitreous by means of the scanning laser ophthalmoscope. Arch Ophthalmol. 1995;113(5):558-560.

27. Sebag J. Age-related changes in human vitreous structure. Graefes Arch Clin Exp Ophthalmol. 1987;225(2):89-93.
Clinical Ophthalmology

\section{Publish your work in this journal}

Clinical Ophthalmology is an international, peer-reviewed journal covering all subspecialties within ophthalmology. Key topics include: Optometry; Visual science; Pharmacology and drug therapy in eye diseases; Basic Sciences; Primary and Secondary eye care; Patient Safety and Quality of Care Improvements. This journal is indexed on PubMed

Submit your manuscript here: http://www.dovepress.com/clinical-ophthalmology-journal

\section{Dovepress}

Central and CAS, and is the official journal of The Society of Clinical Ophthalmology (SCO). The manuscript management system is completely online and includes a very quick and fair peer-review system, which is all easy to use. Visit http://www.dovepress.com/testimonials. php to read real quotes from published authors. 